\title{
Incidence of Febrile Neutropenia in Advanced Breast Cancer Patients Receiving Adjuvant Docetaxel-Doxorubicin-Cyclophosphamide Chemotherapy in Korea and Its Impact on Prognosis
}

\author{
Byeong Kwan Park, M.D., HongKi Gwak, M.D., Seung Taek Lim, M.D., Young Jin Suh, M.D., Ph.D., \\ Ye Won Jeon, M.D., Ph.D. \\ Department of Surgery, The Catholic University, St. Vincent's Hospital, Suwon, Korea
}

Purpose: The concurrent regimen of docetaxel, doxorubicin, and cyclophosphamide (TAC) has been categorized as a high-risk factor for febrile neutropenia (FN). The incidence of FN was reported to be as high as $17 \%-26 \%$ in studies conducted in Western countries. However, these rates may vary among different ethnic groups. This study aimed to evaluate the incidence of FN and its effect on prognosis following adjuvant TAC chemotherapy in Korean patients with advanced breast cancer. Methods: We analyzed data from 187 patients who received 6 cycles of adjuvant TAC chemotherapy between July 2005 and December 2014. No patients received long-acting granulocyte-colony stimulating factor (G-CSF) as primary prophylaxis for FN due to guidelines for cost reimbursement in Korea. The incidence rates of FN, dose reduction of TAC, relative dose intensity (RDI), relapse-free survival (RFS), and overall survival (OS) were investigated. Results: A total of 102 (54.5\%) patients experienced $\mathrm{FN}$, especially older patients (51 years vs. 49 years, $p=0.045)$. RDI was lower in patients with $\mathrm{FN}$ than in those without (96.4\% vs. 99.5\%, $p=0.001$, respectively). Death was reported in 2 patients (2.35\%) without FN and in 10 patients (9.80\%) with FN (hazard ratio [HR]: $6.64 ; 95 \%$ confidence interval [Cl]: 1.28 to 34.36; $p=0.024)$. No significant differences in RFS ( $p=0.235$ ) were found using Kaplan-Meier analysis. Conclusion: The incidence of FN was significantly higher in Korea than in Western countries, and FN had a negative impact on the patients' prognosis. Primary prophylactic G-CSF should be prioritized in Korean patients with advanced breast cancer who receive adjuvant TAC chemotherapy.

Key Words: Breast neoplasms, Chemotherapy, Febrile neutropenia, Prognosis

\section{INTRODUCTION}

Adjuvant systemic chemotherapy is the most important therapeutic modality for locally advanced breast cancer [1,2]. The introduction of anthracycline-containing, taxane-containing, and anthracycline-taxane regimens has greatly improved survival in these patients [3-6]. Clinical guidelines from the American Society of Clinical Oncology (ASCO) and the National Comprehensive Cancer Network (NCCN) in the United States and from the European Organization for Research and Treatment of Cancer (EORTC) recommend the use of concurrent or sequential anthracycline-taxane regimens for the treatment of locally advanced breast cancer $[7,8]$. Although the effectiveness of these

Correspondence: Ye Won Jeon, M.D., Ph.D.

Department of Surgery, St. Vincent's Hospital, College of Medicine, The Catholic University of Korea, 93 Jungbu-daero, Paldal-gu, Suwon 16247, Korea Tel: +82-31-249-8946, Fax: +82-31-247-5347, E-mail: yeswon80@catholic.ac.kr Received: Jun 11, 2019 Revised: Aug 24, 2019 Accepted: Nov 6, 2019 regimens has been demonstrated, this efficacy is often restricted by acute and late toxicities $[9,10]$.

Febrile neutropenia $(\mathrm{FN})$ is the most common toxicity encountered in patients undergoing adjuvant anthracycline-taxane chemotherapy [9]. Chemotherapy-induced FN may predispose patients to life-threatening infections, prolonged hospitalization, modification of the dose or schedule of chemotherapy, and even death [10]. Therefore, prevention of chemotherapy-induced FN in patients undergoing adjuvant anthracycline-taxane regimen chemotherapy is critical.

Recombinant granulocyte-colony stimulating factor (G-CSF) is often administered prophylactically during adjuvant chemotherapy regimens associated with a high incidence of FN [11]. Several clinical guidelines recommend that the use of prophylactic G-CSF should depend on the risk factors for FN during a particular chemotherapy regimen, and, accordingly, regimens have been categorized into high-risk (>20\%), intermediate-risk (10\%-20\%), and low-risk (<20\%) of FN 
$[7,8,11]$.

The concurrent regimen of docetaxel, doxorubicin, and cyclophosphamide (TAC) is often used as an adjuvant chemotherapy regimen in women aged 50 years or less with lymph node-positive, human epidermal growth factor receptor 2 (HER2)-negative breast cancer [12] The Breast Cancer International Research Group (BCIRG) and retrospective analyses suggest that adjuvant TAC chemotherapy is associated with a significant risk of FN and hospitalization, particularly in the absence of primary G-CSF administration $[3,13]$. Therefore, guidelines have categorized this regimen as high-risk for FN $[7,8,11]$. Despite this, primary long-acting G-CSF prophylaxis in patients receiving adjuvant TAC chemotherapy was not covered by public health insurance in Korea until 2014.

The incidence of hematological toxicity caused by adjuvant anthracycline-taxane regimen chemotherapy may vary in different ethnic groups due to differences in the epidemiology of breast cancer and body shape, such as weight, height or body composition, between Asian and Western women. However, there are few reports on the incidence of FN after adjuvant TAC chemotherapy in Asian countries [14]. The aim of this study was to evaluate the incidence of FN in the absence of primary prophylactic G-CSF support, and its effect on prognosis after adjuvant TAC chemotherapy in Korean patients with advanced breast cancer.

\section{METHODS}

\section{Patients}

This retrospective study was approved by the Institutional Review Board (VC18RESI0012). Advanced breast cancer patients (stages II and III) who received adjuvant TAC chemotherapy were identified at the Department of Surgery at The Catholic University, St. Vincent's Hospital between July 2005 and December 2014.

In total, 195 consecutive patients who received adjuvant TAC chemotherapy were included in this study. All patients had histologically confirmed primary breast cancer and underwent complete resection. Eight patients were excluded to minimize other confounding factors, including 5 patients treated with neoadjuvant chemotherapy and 3 patients who did not complete adjuvant TAC chemotherapy. A total of 187 patients were included.

We reviewed patients' characteristics including body weight $(\mathrm{kg})$, height (m), menopausal status, type of surgery, pathological staging, Ki-67 expression, histologic grade, lymphovascular invasion, hormone receptor (HR) expression, HER2 expression, and hormone therapy. HR status was determined using an enzyme immunoassay and reported in the patients' medical records. Immunohistochemistry (IHC), fluorescence in situ hybridization (FISH), or silver in situ hybridization (SISH) were used to evaluate HER2 status, and an IHC score of 0 or +1 or an IHC score of +2 and negative FISH/SISH were defined as negative HER2 overexpression. Tumors were grouped based on HR status, tumor grade, and expression of Ki-67 in luminal A, luminal B, HER2, and triple-negative subtypes.

\section{Treatment}

All patients received a total of 6 cycles of TAC chemotherapy, 3 weeks apart. In each cycle, doxorubicin $\left(50 \mathrm{mg} / \mathrm{m}^{2}\right.$ intravenous [i.v.] for 30 minutes) was initially administered, immediately followed by cyclophosphamide ( $500 \mathrm{mg} / \mathrm{m}^{2}$, i.v. for 1 hour) and docetaxel ( $75 \mathrm{mg} /$ $\mathrm{m}^{2}$, i.v. for 1 hour). All patients received prophylactic corticosteroid for 3 days, beginning 1 day before the start of chemotherapy in a regimen of dexamethasone ( $10 \mathrm{mg}$ i.v.) administered 30 minutes prior to doxorubicin infusion followed by dexamethasone (total $16 \mathrm{mg} /$ day, orally) 1 day after each TAC chemotherapy cycle.

Blood samples were collected before each cycle for complete blood cell counts (CBC) with differential and serum samples retrieved for chemistry assays. After chemotherapy, nadir $\mathrm{CBCs}$ were calculated from day 5. FN was defined as neutropenia $(<500$ neutrophils/ $\mu \mathrm{L}$ or $<1,000$ neutrophils/ $\mu \mathrm{L}$ for over 48 hours) with a febrile event (oral temperature $\geq 38.3^{\circ} \mathrm{C}$ or $\geq 38.0^{\circ} \mathrm{C}$ for over 1 hour) observed by medical staff. All patients with FN received prophylactic antibiotic therapy comprising $1 \mathrm{~g}$ i.v. cefoperazone twice daily and $200 \mathrm{mg}$ tobramycin sulfate once daily, unless contraindicated. Additionally, G-CSF was administered at the start of neutropenia following each cycle, and daily neutrophil and lymphocyte counts were performed subsequently. No patients received long-acting G-CSF or antibiotics as primary prophylaxis for FN during this study period, according to Korean guidelines for cost reimbursement.

Dose reduction was defined as a reduction in the delivered dosage(s) of agent(s) administered relative to the standard values and according to standard toxicity criteria and the physicians' discretion. The chemotherapy relative dose intensity (RDI) was estimated based 
on the ratio of delivered dose intensity (DDI) and the reference standard dose intensity (SDI) [15].

\section{Statistical analysis}

The means and standard deviations of the physiological and demographic characteristics were calculated. A t-test was used to compare the means between 2 categories. Frequencies were compared using two-way tables and chi-square tests. The Kaplan-Meier method and log-rank tests were performed for comparison of survival curves. Relapse-free survival (RFS) was calculated as the time from surgery to diagnosis of recurrent disease in the ipsilateral breast or at a local, regional, or distant site. Overall survival (OS) was defined as the time from initial diagnosis of primary breast cancer to death from any cause. Multivariate analyses were conducted using the Cox proportional hazard regression model to evaluate the correlation of FN with RFS and OS. Two-sided tests were performed, with a $p$-value $<0.05$ considered statistically significant. All statistical analyses were performed using SAS software for Windows (Version 9.2, SAS Institute, Cary, USA).

\section{RESULTS}

A total of 187 patients who completed 6 cycles of adjuvant TAC chemotherapy were included in this study. Baseline and treatment characteristics were compared between patients with and without reported FN during adjuvant TAC chemotherapy (Table 1). For all patients, the mean age at breast cancer diagnosis was 49 years (range, 20 to 70 years). There were no significant differences in body mass index (BMI), type of surgery, tumor stage, Ki-67 expression, histologic grade, lymphovascular invasion, or in HR or HER2 status between the two groups.

Table 1. Continued

\begin{tabular}{|c|c|c|c|c|}
\hline Characteristic & $\begin{array}{c}\text { All patients } \\
(n=187) \\
\text { No. }(\%)\end{array}$ & $\begin{array}{c}\text { Without FN } \\
(n=85) \\
\text { No. }(\%)\end{array}$ & $\begin{array}{c}\text { With FN } \\
(n=102) \\
\text { No. }(\%)\end{array}$ & $p$-value \\
\hline \multicolumn{5}{|l|}{ PR status } \\
\hline Positive & $94(50.3)$ & $46(54.1)$ & $48(47.1)$ & 0.336 \\
\hline Negative & $93(49.7)$ & $39(45.9)$ & $54(52.9)$ & \\
\hline \multicolumn{5}{|l|}{ HER2 status } \\
\hline Positive & $64(34.2)$ & $35(41.2)$ & $29(28.4)$ & 0.067 \\
\hline Negative & $123(65.8)$ & $50(58.8)$ & $73(71.6)$ & \\
\hline $\mathrm{Ki} 67^{\dagger}$ & $\begin{array}{c}30.6 \pm 25.3 \\
25.0(1.0-90.0)\end{array}$ & $\begin{array}{c}29.7 \pm 26.1 \\
20.0(1.0-90.0)\end{array}$ & $\begin{array}{c}31.3 \pm 24.8 \\
25.0(1.0-90.0)\end{array}$ & 0.405 \\
\hline \multicolumn{5}{|c|}{ Histological grade } \\
\hline G1-2 & $99(52.9)$ & $43(50.6)$ & $56(54.9)$ & 0.556 \\
\hline G3 & $88(47.1)$ & $42(49.4)$ & $46(45.1)$ & \\
\hline \multicolumn{5}{|l|}{$\begin{array}{l}\text { Lymphovascular } \\
\text { invasion }\end{array}$} \\
\hline Positive & $92(49.2)$ & $44(51.8)$ & $48(47.1)$ & 0.521 \\
\hline Negative & $95(50.8)$ & $41(48.2)$ & $54(52.9)$ & \\
\hline \multicolumn{5}{|l|}{ Subtype } \\
\hline Luminal A & $34(18.2)$ & $19(22.4)$ & $15(14.7)$ & 0.443 \\
\hline Luminal B & $86(46.0)$ & $38(44.7)$ & $48(47.1)$ & \\
\hline HER2 & $34(18.2)$ & $16(18.8)$ & $18(17.7)$ & \\
\hline Triple negative & $33(17.7)$ & $12(14.1)$ & $21(20.6)$ & \\
\hline \multicolumn{5}{|c|}{ Hormonal therapy } \\
\hline Yes & $120(64.2)$ & $56(65.9)$ & $64(62.8)$ & 0.656 \\
\hline No & $67(35.8)$ & $29(34.1)$ & $38(37.3)$ & \\
\hline
\end{tabular}

$\mathrm{FN}$ = febrile neutropenia; $\mathrm{BMI}=$ body mass index; $\mathrm{ER}=$ estrogen receptor; $\mathrm{PR}=$ progesterone receptor; HER2 = human epidermal growth factor receptor 2. ${ }^{*}$ Median (range); ${ }^{\dagger}$ Mean \pm SD (range).
Table 1. Patients and tumor characteristics

\begin{tabular}{|c|c|c|c|c|}
\hline Characteristic & $\begin{array}{c}\text { All patients } \\
(\mathrm{n}=187) \\
\text { No. }(\%)\end{array}$ & $\begin{array}{l}\text { Without FN } \\
(n=85) \\
\text { No. }(\%)\end{array}$ & $\begin{array}{c}\text { With FN } \\
(n=102) \\
\text { No. }(\%)\end{array}$ & $p$-value \\
\hline Age $(y r)^{*}$ & $49.0(20.0-70.0)$ & $49.0(20.0-68.0)$ & $51.0(26.0-70.0)$ & 0.045 \\
\hline$<40$ & $18(9.6)$ & $10(11.8)$ & $8(7.8)$ & \\
\hline$\geq 40$ & $169(90.4)$ & 75 (88.2) & $94(92.2)$ & \\
\hline $\operatorname{BMI}\left(\mathrm{kg} / \mathrm{m}^{2}\right)^{*}$ & $23.7(16.6-36.0)$ & $23.5(18.1-34.7)$ & $23.8(16.6-36.0)$ & 0.104 \\
\hline \multicolumn{5}{|l|}{ Menopause } \\
\hline Premenopausal & $87(46.5)$ & $47(55.3)$ & $40(39.2)$ & \multirow[t]{2}{*}{0.028} \\
\hline Postmenopausal & $100(53.5)$ & $38(44.7)$ & $62(60.8)$ & \\
\hline \multicolumn{5}{|c|}{ Type of surgery } \\
\hline Mastectomy & $81(43.3)$ & $41(48.2)$ & $40(39.2)$ & \multirow[t]{2}{*}{0.215} \\
\hline $\begin{array}{l}\text { Breast conserving } \\
\text { surgery }\end{array}$ & $106(56.7)$ & $44(51.8)$ & $62(60.8)$ & \\
\hline \multicolumn{5}{|l|}{ Pathological T stage } \\
\hline $\mathrm{T} 1$ & $80(42.8)$ & $37(43.5)$ & $43(42.2)$ & \multirow[t]{3}{*}{0.288} \\
\hline $\mathrm{T} 2$ & $93(49.7)$ & $39(45.9)$ & $54(52.9)$ & \\
\hline T3 & $14(7.5)$ & $9(10.6)$ & $5(4.9)$ & \\
\hline \multicolumn{5}{|c|}{ Pathological N stage } \\
\hline No & $3(1.6)$ & 0 & $3(2.9)$ & \multirow[t]{4}{*}{0.489} \\
\hline N1 & $114(61.0)$ & $51(60.0)$ & $63(61.8)$ & \\
\hline N2 & $45(24.1)$ & $21(24.7)$ & $24(23.5)$ & \\
\hline N3 & $25(13.4)$ & $13(15.3)$ & $12(11.8)$ & \\
\hline \multicolumn{5}{|l|}{ Stage } \\
\hline$\|$ & $113(60.4)$ & $46(54.1)$ & $67(65.7)$ & \multirow[t]{2}{*}{0.107} \\
\hline III & $74(39.6)$ & $39(45.9)$ & $35(34.3)$ & \\
\hline \multicolumn{5}{|l|}{ ER status } \\
\hline Positive & $116(62.0)$ & $55(64.7)$ & $61(59.8)$ & \multirow[t]{2}{*}{0.491} \\
\hline Negative & 71 (38.0) & $30(35.3)$ & $41(40.2)$ & \\
\hline
\end{tabular}

(Continued to the next) 


\section{FN during adjuvant TAC chemotherapy}

During adjuvant TAC chemotherapy, 102 (54.5\%) patients experienced FN. No significant differences in time from surgery to the first cycle of chemotherapy between the groups were observed. FN was more frequently observed in older patients (51 years vs. 49 years, $p=0.045)$ and in those with a conferred postmenopausal status (60.8\% vs. $44.7 \%, p=0.028)$. In baseline blood tests, no significant differences in white blood cell counts, platelet counts, neutrophil-lymphocyte ratio (NLR), or platelet-lymphocyte ratio (PLR) were found between the groups (Table 2).

From the 187 patients, 64 (34.2\%) experienced FN in the 1st chemotherapy cycle, and 45 (24.1\%) and 44 (23.5\%) experienced FN in the 4 th and 5th chemotherapy cycles, respectively. Of the 102 patients who experienced FN during adjuvant TAC chemotherapy, 64 (62.8\%) experienced FN in the 1st chemotherapy cycle, 35 (34.3\%), 43 (42.2\%), and 45 (44.1\%) experienced their first FN event in the 2nd, 3rd, and 4th chemotherapy cycles, respectively. Furthermore, 72 patients (70.6\%) experienced FN in more than 2 cycles (Table 2).

Dose reduction was registered in 33 patients (17.6\%). Dose reduction during adjuvant TAC chemotherapy was more frequently observed in patients who experienced FN than in patients who did not experience FN (29.4\% vs. $3.5 \%, p=0.001$, respectively), and the RDI was lower in patients who experienced FN than in those who did not (96.4\% vs. 99.5\%, $p=0.001$, respectively). An RDI below 85.0\% during adjuvant TAC chemotherapy was observed in 2 (2.0\%) of the 102 patients who had FN but not in patients who did not experience FN (Table 2).

Table 2. Characteristics of chemotherapy and baseline blood tests

\begin{tabular}{|c|c|c|c|c|}
\hline Characteristic & $\begin{array}{c}\text { All patients }(n=187) \\
\text { No. }(\%)\end{array}$ & $\begin{array}{c}\text { Without FN }(n=85) \\
\text { No. }(\%)\end{array}$ & $\begin{array}{l}\text { With FN }(n=102) \\
\text { No. }(\%)\end{array}$ & $p$-value \\
\hline Time from surgery to chemotherapy (day)* & $15.0(7.0-60.0)$ & $15.0(7.0-60.0)$ & $15.0(8.0-50.0)$ & 0.952 \\
\hline \multicolumn{5}{|l|}{ Patients experienced FN } \\
\hline 1st cycle & $64(34.2)$ & & $64(62.8)$ & \\
\hline 2nd cycle & $35(18.7)$ & & $35(34.3)$ & \\
\hline 3rd cycle & $43(23.0)$ & & $43(42.2)$ & \\
\hline 4th cycle & $45(24.1)$ & & $45(44.1)$ & \\
\hline 5th cycle & $44(23.5)$ & & $44(43.1)$ & \\
\hline 6th cycle & $28(15.0)$ & & $28(27.5)$ & \\
\hline \multicolumn{5}{|l|}{ Number of cycle experienced FN } \\
\hline 1 cycle & $30(16.0)$ & & $30(29.4)$ & \\
\hline 2 cycles & $32(17.1)$ & & $32(31.4)$ & \\
\hline 3 cycles & $16(8.6)$ & & $16(15.7)$ & \\
\hline 4 cycles & $10(5.4)$ & & $10(9.8)$ & \\
\hline 5 cycles & $12(6.4)$ & & $12(11.7)$ & \\
\hline 6 cycles & $2(1.1)$ & & $2(2.0)$ & \\
\hline Dose reduction & $33(17.6)$ & $3(3.5)$ & $30(29.4)$ & 0.001 \\
\hline RDI (\%) & 97.8 & 99.5 & 96.4 & 0.001 \\
\hline $\mathrm{RDI}<85.0 \%$ & $2(1.1)$ & 0 & $2(2.0)$ & 0.293 \\
\hline \multicolumn{5}{|l|}{ Baseline blood test } \\
\hline WBC (Cells $/ \mu \mathrm{L})^{\dagger}$ & $\begin{array}{r}6,447.5 \pm 1,719.6 \\
(2,640.0-12,410.0)\end{array}$ & $\begin{array}{r}6,326.2 \pm 1,609.0 \\
(2,820.0-10,570.0)\end{array}$ & $\begin{array}{c}6,548.5 \pm 1,808.3 \\
(2,640.0-12,410.0)\end{array}$ & 0.343 \\
\hline Neutrophil (\%) & $56.0 \pm 10.2$ & $56.1 \pm 9.7$ & $55.9 \pm 10.7$ & \\
\hline Lymphocyte (\%) & $34.8 \pm 9.3$ & $34.7 \pm 8.7$ & $34.9 \pm 9.8$ & \\
\hline $\mathrm{N} / \mathrm{L}$ ratio* & $\begin{array}{c}1.8 \pm 1.0 \\
1.6(0.5-8.4)\end{array}$ & $\begin{array}{c}1.8 \pm 0.9 \\
1.6(0.5-6.5)\end{array}$ & $\begin{array}{c}1.9 \pm 1.1 \\
1.6(0.6-8.4)\end{array}$ & 0.869 \\
\hline Platelet $\left(10^{3} \text { cells } / \mu \mathrm{L}\right)^{\dagger}$ & $\begin{array}{l}262.1 \pm 59.5 \\
(91.0-494.0)\end{array}$ & $\begin{array}{l}267.3 \pm 62.7 \\
(146.0-494.0)\end{array}$ & $\begin{array}{l}257.8 \pm 56.6 \\
(91.0-393.0)\end{array}$ & 0.568 \\
\hline P/L ratio* & $\begin{array}{c}129.8 \pm 46.1 \\
124.7(56.9-310.0)\end{array}$ & $\begin{array}{c}133.6 \pm 43.6 \\
130.1(60.2-252.7)\end{array}$ & $\begin{array}{c}126.7 \pm 48.1 \\
119.8(56.9-310.0)\end{array}$ & 0.122 \\
\hline Albumin $(\mathrm{g} / \mathrm{dL})^{+}$ & $4.5 \pm 0.2(3.7-5.2)$ & $4.5 \pm 0.2(4.0-5.2)$ & $4.4 \pm 0.2(3.7-4.9)$ & 0.182 \\
\hline
\end{tabular}

$\mathrm{FN}=$ febrile neutropenia; $\mathrm{RDI}=$ relative dose intensity; $\mathrm{WBC}=$ white blood cell; $\mathrm{N} / \mathrm{L}$ ratio = neutrophil-lymphocyte ratio; $\mathrm{P} / \mathrm{L}$ ratio = platelet-lymphocyte ratio. ${ }^{*}$ Median (range); ${ }^{\dagger}$ Mean \pm SD (range). 


\section{FN and survival outcomes}

At the median follow-up time of 84 months (range, 11-160), we did not observe a significant difference in survival outcomes between the patients with or without reported FN. A total of 23 relapses were confirmed, and the median time to relapse was 25 months (range, 11-111) from diagnosis to relapse in the entire cohort. The 5- and 10-year RFS rates for patients who did not experience FN were $92.0 \%$ and $86.0 \%$, respectively and for those patients who experienced FN were 87.0\% and $82.0 \%$, respectively. Relapse rates were $9.41 \%$ for patients who did not experience $\mathrm{FN}$ and $14.70 \%$ for patients who experienced FN (hazard ratio, HR: $2.19 ; 95 \%$ confidence interval, CI: 0.83 to $5.78 ; p=0.111$ ), with most relapses including disease at a distant site. No significant differences in RFS ( $p=0.235$, Figure 1A) were found after KaplanMeier modeling.

Overall, 12 patients died, with the median time from diagnosis to death being 36 months (11-135). The 5- and 10-year OS rates for patients who did not experience FN were $98.0 \%$ and $96.0 \%$, respectively and for those who experienced FN were $93.0 \%$ and $88.0 \%$, respectively. Two (2.35\%) patients who did not experience FN and $10(9.80 \%)$ who experienced FN (HR: 6.64; 95\% CI: 1.28 to $34.36 ; p=0.024$ ) died. Kaplan-Meier modeling showed that FN was significantly associated with poorer OS ( $p=0.040$, Figure 1B).

In the multivariate Cox regression analysis, stage (HR: 2.88; 95\% CI: 1.14 to $7.27 ; p=0.025$ ) and a histologic grade of 3 (HR: $3.75 ; 95 \% \mathrm{CI}$ : 1.36 to $10.35 ; p=0.011$ ) were significantly associated with an elevated risk of relapse. Tumor stage (HR: 5.13; 95\% CI: 1.24 to 21.30; $p=0.024$ ) was significantly associated with increased risk of mortality. Menopausal status, lymphovascular invasion, HR status and HER2 status did not significantly affect RFS or OS rates (Table 3).

\section{DISCUSSION}

The overall incidence of FN during adjuvant TAC chemotherapy observed in this study was $54.5 \%$. Due to the unavailability of long-acting G-CSF as primary prophylaxis for $\mathrm{FN}$ for advanced breast cancer patients, this reflects the real incidence of FN during adjuvant TAC chemotherapy in Korea. FN was also associated with a negative prognosis.

In Western countries, $\mathrm{FN}$ is an increasingly common side effect of modern anthracycline-taxane-based chemotherapy regimens. Boer et al. [16] observed a higher incidence of neutropenia (76\%) in the TAC group than in the fluorouracil, doxorubicin, and cyclophosphamide (FAC) group (22\%), as well as a higher incidence of FN in the former group than in the latter (26\% vs. $0 \%$, respectively). In the BCIRG 001 trial, in which primary prophylactic G-CSF was not used, the incidence of FN in the TAC arm (745 patients) was 24.7\% [3]. The BCIRG 0015 trial reported that the incidence of FN in the TAC arm (1635 patients) was $17 \%$ [17]. In this study, the overall incidence of FN during adjuvant TAC chemotherapy was 54.5\% (102/187), a significantly higher frequency than that observed in previous studies conducted in
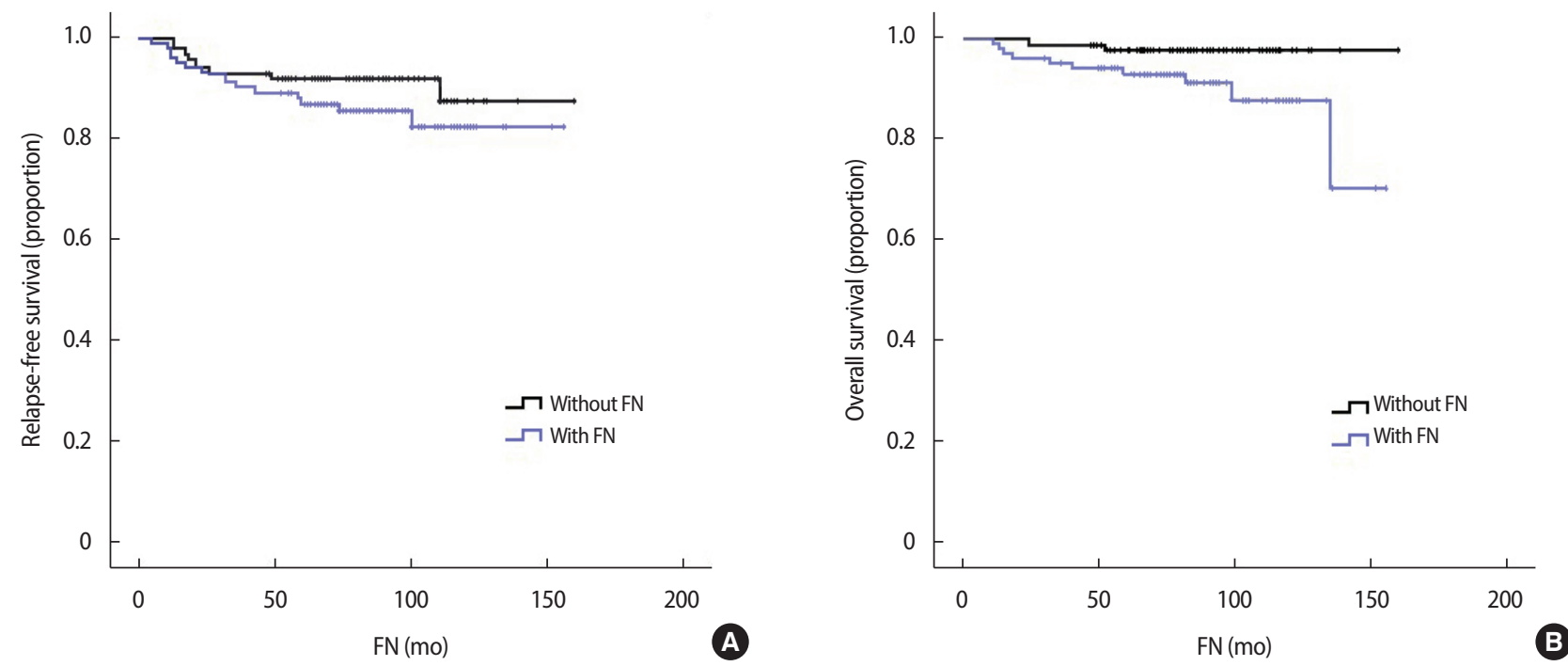

Figure 1. (A) Relapse-free survival (RFS, $p=0.235$ ) and (B) overall survival (OS, $p=0.040$ ), according to the occurrence of febrile neutropenia (FN). 
Table 3. Cox proportional hazard regression for relapse-free survival (RFS) and overall survival (OS)

\begin{tabular}{|c|c|c|c|c|c|c|c|c|}
\hline \multirow[b]{2}{*}{ Characteristic } & \multicolumn{4}{|c|}{ RFS } & \multicolumn{4}{|c|}{ OS } \\
\hline & $\begin{array}{c}\text { HR } \\
(95 \% \mathrm{Cl})\end{array}$ & $p$-value & $\begin{array}{c}\text { Adjust HR } \\
(95 \% \mathrm{Cl})\end{array}$ & $p$-value & $\begin{array}{c}\mathrm{HR} \\
(95 \% \mathrm{Cl})\end{array}$ & $p$-value & $\begin{array}{c}\text { Adjust HR } \\
(95 \% \mathrm{Cl})\end{array}$ & $p$-value \\
\hline \multicolumn{9}{|l|}{ Menopause } \\
\hline Premenopausal & reference & & reference & & reference & & reference & \\
\hline Postmenopausal & $1.07(0.45-2.56)$ & 0.877 & $1.26(0.38-4.15)$ & 0.707 & $1.13(0.34-3.73)$ & 0.846 & $1.21(0.24-3.14)$ & 0.831 \\
\hline \multicolumn{9}{|l|}{ Stage } \\
\hline$\|$ & reference & & reference & & reference & & reference & \\
\hline III & $2.83(1.13-7.13)$ & 0.027 & $2.88(1.14-7.27)$ & 0.025 & $5.09(1.33-19.47)$ & 0.017 & $5.13(1.24-21.30)$ & 0.024 \\
\hline \multicolumn{9}{|l|}{ Histological grade } \\
\hline G1-2 & reference & & reference & & reference & & reference & \\
\hline G3 & $3.77(1.37-10.40)$ & 0.010 & $3.75(1.36-10.35)$ & 0.011 & $3.20(0.85-12.09)$ & 0.085 & $3.26(0.87-13.15)$ & 0.080 \\
\hline \multicolumn{9}{|c|}{ Lymphovascular invasion } \\
\hline Negative & reference & & reference & & reference & & reference & \\
\hline Positive & $2.17(0.86-5.45)$ & 0.099 & $2.17(0.87-5.46)$ & 0.098 & $3.13(0.83-11.84)$ & 0.0925 & $3.30(0.85-12.07)$ & 0.088 \\
\hline \multicolumn{9}{|c|}{ Febrile neutropenia (FN) } \\
\hline No & reference & & reference & & reference & & reference & \\
\hline Yes & $2.10(0.80-5.46)$ & 0.129 & $2.19(0.83-5.78)$ & 0.111 & $4.57(0.97-21.45)$ & 0.054 & $6.64(1.28-34.36)$ & 0.024 \\
\hline \multicolumn{9}{|l|}{ ER status } \\
\hline Positive & reference & & reference & & reference & & reference & \\
\hline Negative & $1.65(0.68-3.97)$ & 0.266 & $1.63(0.67-3.94)$ & 0.282 & $1.36(0.42-4.49)$ & 0.609 & $1.26(0.39-4.30)$ & 0.802 \\
\hline \multicolumn{9}{|l|}{ PR status } \\
\hline Positive & reference & & reference & & reference & & reference & \\
\hline Negative & $1.59(0.65-3.89)$ & 0.313 & $1.57(0.64-3.87)$ & 0.323 & $1.32(0.40-4.35)$ & 0.643 & $1.31(0.40-4.29)$ & 0.623 \\
\hline \multicolumn{9}{|l|}{ HER2 status } \\
\hline Positive & reference & & reference & & reference & & reference & \\
\hline Negative & $2.17(0.73-6.50)$ & 0.165 & $2.15(0.72-6.45)$ & 0.170 & NA & NA & NA & NA \\
\hline
\end{tabular}

$\mathrm{HR}=$ hazard ratio; $\mathrm{Cl}=$ confidence interval; $\mathrm{ER}=$ estrogen receptor; $\mathrm{PR}=$ progesterone receptor; $\mathrm{HER} 2=$ human epidermal growth factor receptor 2 .

Western countries $(17 \%-26 \%)$. However, our results were consistent with incidence ratios reported in two previous studies in Korea [14,18]. Woo et al. [18] found that $98.8 \%$ (79/80) of patients developed neutropenia (grade 3/4) and 42.5\% (34/80) of patients developed FN. Lee et al. [14] reported neutropenia (grade $3 / 4$ ) in $73.5 \%$ of patients (30/41) and FN in $63.4 \%$ (26/41). Beyond the role of well-established and recognized clinical predictive factors, such as age over 65 years, advanced disease, poor performance status, and other comorbidities, which may influence the occurrence of FN, these findings may be influenced by inter-individual variations in docetaxel and doxorubicin pharmacokinetics and pharmacodynamics, as well as by interethnic differences in docetaxel- and doxorubicin-induced myelosuppression $[19,20]$. Despite progress in this area, predictive factors for FN need to be re-evaluated and redefined by analyses beyond classical patients and biochemical factors, and include integration of large-scale pharmacogenomic inter-variability.

The risk of an episode of FN is greater during the first cycle of treat- ment when patients are typically receiving full-dose intensity chemotherapy [20]. A recent prospective cohort study including 1202 patients with stage I-III breast cancer using a new chemotherapy regimen was conducted at 115 US sites and showed that the majority of neutropenic events (59\%; 116 of 196) and infections (55\%; 179 of 325) occurred during the initial cycle of chemotherapy [21]. Consistent with their findings, $62.8 \%$ of patients (64 of 102) in our study experienced $\mathrm{FN}$ in the first chemotherapy cycle. A total of $5.9 \%, 12.7 \%$, and $8.8 \%$ of patients experienced their first FN event in the 2nd, 3rd, and 4th chemotherapy cycles, respectively. Moreover, the overall incidence of FN was maintained above $20 \%$ in the 1st chemotherapy cycle but also in the subsequent 4 th and 5 th chemotherapy cycles.

Previous studies have been conducted to investigate the impact of FN on breast cancer treatment outcomes $[20,22,23]$. Over time, growing evidence has emerged showing that a decrease in chemotherapy RDI, commonly caused by FN, is a key factor in the assessment of adjuvant chemotherapy efficacy. Several retrospective and prospective 
studies support the importance of chemotherapy dose intensity in achieving optimal clinical survival outcomes (e.g., disease free survival [DFS], and OS) [20,22,23]. In our study, RDI was significantly lower in patients who experienced FN (96.4\% vs. 99.5\%, $p=0.001)$. Furthermore, an RDI below $85.0 \%$ during adjuvant TAC chemotherapy was observed in 2 (2.0\%) of 102 patients who experienced FN but not observed in patients with no registered FN episodes. As a result, FN was significantly associated with poorer OS $(2.35 \%$ vs. $9.80 \%, p=0.024)$. Although RFS was not significantly different between the two groups ( $9.41 \%$ vs. $14.70 \%, p=0.111)$, there was an observed difference of $5.3 \%$.

Our study has some limitations, one being its retrospective nature. The number of patients was small because only patients who received adjuvant TAC chemotherapy in a single institution were included. However, no other study has evaluated the overall incidence of FN and its effect on prognosis after adjuvant TAC chemotherapy in Asian women, including in Korean patients. Most studies in this area were performed in Western countries. In addition, the follow-up period of our study may not have been sufficient to evaluate patients with late recurrences or death, which can occur 10 years after the initial treatment. This study did not include data on other chronic comorbidities that might have a correlation with the incidence of FN. Chia et al. [24] found that chronic comorbidities such as congestive heart failure, osteoarthritis, previous cancer diagnosis, pre-treatment for renal and liver function, were all associated with an increased risk of FN [14]. Therefore, it remains unknown whether these factors may have affected the risk of FN in our study.

In conclusion, our study demonstrated that the overall incidence of FN during adjuvant TAC chemotherapy in a single-center Korean cohort of patients was significantly higher than that reported in studies conducted in Western countries. Furthermore, FN incidence was maintained above $20 \%$ until the last chemotherapy cycle and was associated with a poorer prognosis. Therefore, the addition of supportive treatment such as primary prophylactic G-CSF throughout the chemotherapy cycles should be prioritized for Korean patients with advanced breast cancer receiving adjuvant TAC chemotherapy.

\section{CONFLICTS OF INTEREST}

The authors declare that they have no competing interests.

\section{ACKNOWLEDGMENTS}

Statistical analysis support was provided by the Catholic Research Coordinating Center of the Korea Health 21 R\&D Project (A070001), Ministry of Health \& Welfare, Republic of Korea.

\section{REFERENCES}

1. Gradishar WJ, Anderson BO, Balassanian R, Blair SL, Burstein HJ, Cyr A, et al. Breast cancer version 2.2015. J Natl Compr Canc Netw 2015;13:448-75.

2. Senkus E, Kyriakides S, Penault-Llorca F, Poortmans P, Thompson A, Zackrisson S, et al. Primary breast cancer: ESMO clinical practice guidelines for diagnosis, treatment and follow-up. Ann Oncol 2013;24:vi7-23.

3. Mackey JR, Martin M, Pienkowski T, Rolski J, Guastalla JP, Sami A, et al. Adjuvant docetaxel, doxorubicin, and cyclophosphamide in node-positive breast cancer: 10-year follow-up of the phase 3 randomised BCIRG 001 trial. Lancet Oncol 2013;14:72-80.

4. Martin M, Pienkowski T, Mackey J, Pawlicki M, Guastalla JP, Weaver C, et al. Adjuvant docetaxel for node-positive breast cancer. N Engl J Med 2005;352:2302-13.

5. Roche H, Fumoleau P, Spielmann M, Canon JL, Delozier T, Serin D, et al. Sequential adjuvant epirubicin-based and docetaxel chemotherapy for node-positive breast cancer patients: the FNCLCC PACS 01 Trial. J Clin Oncol 2006;24:5664-71.

6. Martin M, Rodriguez-Lescure A, Ruiz A, Alba E, Calvo L, Ruiz-Borrego M, et al. Randomized phase 3 trial of fluorouracil, epirubicin, and cyclophosphamide alone or followed by paclitaxel for early breast cancer. J Natl Cancer Inst 2008;100:805-14.

7. Aapro MS, Bohlius J, Cameron DA, Lago LD, Donnelly JP, Kearney N, et al. 2010 update of EORTC guidelines for the use of granulocyte-colony stimulating factor to reduce the incidence of chemotherapy-induced febrile neutropenia in adult patients with lymphoproliferative disorders and solid tumours. Eur J Cancer 2011;47:832.

8. Smith TJ, Khatcheressian J, Lyman GH, Ozer H, Armitage JO, Balducci L, et al. 2006 update of recommendations for the use of white blood cell growth factors: an evidence-based clinical practice guideline. J Clin Oncol 2006;24:3187-205. 
9. Dale DC. Colony-stimulating factors for the management of neutropenia in cancer patients. Drugs 2002;62:1-15.

10. Kuderer NM, Dale DC, Crawford J, Lyman GH. Impact of primary prophylaxis with granulocyte colony-stimulating factor on febrile neutropenia and mortality in adult cancer patients receiving chemotherapy: a systematic review. J Clin Oncol 2007;25:3158-67.

11. Bennett CL, Djulbegovic B, Norris LB, Armitage JO. Colony-stimulating factors for febrile neutropenia during cancer therapy. N Engl J Med 2013;368:1131-9.

12. Lupichuk S, Tilley D, Kostaras X, Joy AA. Real-world adjuvant TAC or FEC-D for HER2-negative node-positive breast cancer in women less than 50 years of age. Curr Oncol 2016;23:164-70.

13. Barcenas CH, Niu J, Zhang N, Zhang Y, Buchholz TA, Elting LS, et al. Risk of hospitalization according to chemotherapy regimen in early-stage breast cancer. J Clin Oncol 2014;32:2010-7.

14. Lee J, Ahn MH, Jang YH, Lee EJ, Park JH, Rho J, et al. Toxicity and quality of life of Korean breast cancer patients treated with docetaxelcontaining chemotherapy without primary G-CSF prophylaxis. Breast Cancer 2014;21:670-6.

15. Weycker D, Barron R, Edelsberg J, Kartashov A, Lyman GH. Incidence of reduced chemotherapy relative dose intensity among women with early stage breast cancer in US clinical practice. Breast Cancer Res Treat 2012;133:301-10.

16. Boer K, Lang I, Juhos E, Pinter T, Szanto J. Adjuvant therapy of breast cancer with docetaxel-containing combination (TAC). Pathol Oncol Res 2003;9:166-9.

17. Mackey JR, Pienkowski T, Crown J, Sadeghi S, Martin M, Chan A, et al. Long-term outcomes after adjuvant treatment of sequential versus combination docetaxel with doxorubicin and cyclophosphamide in node-positive breast cancer: BCIRG-005 randomized trial.
Ann Oncol 2016;27:1041-7.

18. Woo HD, Kim HS, Lee JH, Kim HM, Han SW, Kim SY, et al. Toxicity and tolerability study of adjuvant TAC regimen chemotherapy in Korean patients with breast cancer. J Breast Cancer 2011;14:S44-9.

19. Hor SY, Lee SC, Wong CI, Lim YW, Lim RC, Wang LZ, et al. PXR, CAR and HNF4alpha genotypes and their association with pharmacokinetics and pharmacodynamics of docetaxel and doxorubicin in Asian patients. Pharmacogenomics J 2008;8:139-46.

20. Lalami Y, Klastersky J. Impact of chemotherapy-induced neutropenia (CIN) and febrile neutropenia (FN) on cancer treatment outcomes: an overview about well-established and recently emerging clinical data. Crit Rev Oncol Hematol 2017;120:163-79.

21. Culakova E, Poniewierski MS, Wolff DA, Dale DC, Crawford J, Lyman GH. The impact of chemotherapy dose intensity and supportive care on the risk of febrile neutropenia in patients with early stage breast cancer: a prospective cohort study. Springerplus 2015;4:396405.

22. Chirivella I, Bermejo B, Insa A, Perez-Fidalgo A, Magro A, Rosello S, et al. Optimal delivery of anthracycline-based chemotherapy in the adjuvant setting improves outcome of breast cancer patients. Breast Cancer Res Treat 2009;114:479-84.

23. Colleoni M, Price K, Castiglione-Gertsch M, Goldhirsch A, Coates A, Lindtner J, et al. Dose-response effect of adjuvant cyclophosphamide, methotrexate, 5-fluorouracil (CMF) in node-positive breast cancer. International breast cancer study group. Eur J Cancer 1998; 34:1693-700.

24. Chia VM, Page JH, Rodriguez R, Yang SJ, Huynh J, Chao C. Chronic comorbid conditions associated with risk of febrile neutropenia in breast cancer patients treated with chemotherapy. Breast Cancer Res Treat 2013;138:621-31. 